\title{
Characteristics of Consumer Behavior in China's New Energy Vehicles Market
}

\author{
Mingwei Sun ${ }^{1}$ \\ ${ }^{1}$ International College Beijing, China Agricultural \\ University
}

\begin{abstract}
With the development of vehicle market, it brings higher quality of life to consumers and countless profits to enterprises. At the same time, the growing severe environmental problems require reform in the automobile industry and all the signs indicate that new energy vehicle is the most feasible solution. Nevertheless, it is still a less popular idea in China. This research aims to figure out the factors that influence Chinese consumers' decisions on purchasing a new energy vehicle and propose rational suggestions to the Chinese new energy vehicle industry to raise the trend of consuming green energy.
\end{abstract}

Keywords: consumer behavior, new energy vehicles, business administration

\section{INTRODUCTION}

\subsection{Development overview of new energy vehicles in other countries}

Back to 1960s, the western developed countries had established research institutions, injecting the most advanced technology in new energy vehicles area. They also enacted laws and policy in the following time, providing a favorable environment for the development of new energy vehicles.

Since President Obama took the office, who is a liberal democrat, highly supporting the green energy issue, government appropriated more than $\$ 2.4$ billion supporting the research of core technology and design of manufacturing for key parts; the appropriation was also used to enlarge government spending and purchasing subsidy on new energy vehicles, giving financial support to build the supporting facilities like charging pile ${ }^{[1]}$. By a series of implements, in June 2013, according to the published sales report, only within six months, the total sales of hybrid electric vehicles and electric vehicles had approached 287,000 with a $23 \%$ increase, breaking the historical record ${ }^{[2]}$.

The development of new energy vehicles in France is fairly mature. In early 1990s, the total output of new energy vehicles reached 18,000,000 and more than 240 public charging piles inside the country, forming an integrated system which contains research, manufacture, policy and

\author{
Zhiqiang Luan $^{2}$ \\ ${ }^{2}$ Corresponding author, International College Beijing, \\ China Agricultural University
}

marketing ${ }^{[1]}$. All the successive governments keep the idea of supporting new energy programs, which pushes the vigor of the entire industry, establishing a virtuous interaction that the government encourages the enterprises to develop and the enterprises do have incentive to improve the production.

\subsection{Development overview of new energy vehicles in Chinese market}

The origin of new energy vehicles development in China can be traced back to " 863 " program in 2001, which aims to support the research on the whole design and the key parts by investing more than $3.2 \mathrm{rmb}$ billion and organizing numerous outstanding scientists ${ }^{[1]}$. Chinese government successively enacted several policies to encourage the production and purchase of new energy vehicles, planning to enlarge the new energy vehicles industry. One policy proposed in 2009 appointed that Beijing, Shanghai, Chongqing and other 10 cities as demonstration promote pilot cities to popularize the new energy vehicles. Nevertheless, up to the end of 2012, none of the demonstration promote pilot cities had accomplished even $50 \%$ of the prospective goal $^{[3]}$. According to the report, in the first half year of 2013, the total production of the new energy vehicles were 5885 and the total sales were 5889, with a $56.3 \%$ increase and a $42.7 \%$ increase respectively compared with corresponding period of $2012^{[2]}$.

\subsection{The problem of new energy vehicles development in Chinese market}

Compared with other developed countries, it is no doubt that China still has a large gap on developing new energy vehicles industry. The consuming market is at beginning phase, and the existing several essential problems can be classified into 4 categories: the uncertainty of the market; the problem of supporting facilities; the high sales and relevant price; the bottleneck of core technology.

\subsubsection{The bottleneck of core technology}

Though the Chinese government has put numerous money and efforts into studying the core technology of new energy vehicles and designing the manufacturing for key parts, it still remains on the level of mimicking the developed countries. Therefore, the passive situation is hard to make a profit that is the crucial reason why currently the development of new energy vehicles can't be highly improved. 


\subsubsection{The high sales and relevant price}

For new energy vehicles are the newly sprouted things to Chinese market, high research cost requires a high sales price. It is also caused by the low production level which means that if it can become a mass production industry, the price will be pushed down. The relevant cost such as maintenance cost is high as well in that this newly sprouted industry has not attracted lots of investments to popularize it.

\subsubsection{The problem of supporting facilities}

Unlike some developed countries where the supporting facilities are highly popularized, China can't achieve that kind of high level. For there are very few public charging piles inside the country, it usually costs customers lots of time to find a place to charge their new energy vehicles. And the efficiency of charging pile is low that an electric vehicle will spend at least half an hour to be full charged.

\subsubsection{The uncertainty of the market}

For new energy vehicles is still a new concept to most of the Chinese people, not only individual customers but also most of the enterprises and organizations are lack of the knowledge about this new kind of vehicles. And the whole industry just opened its door for quite a short time, which cannot provide a mature system to the public. Therefore, customers are not familiar with the new energy vehicles and do not have confidence on purchasing due to the potential risk.

\section{Design of Questionnaire and investigation of consumers}

The questionnaire can be divided into two parts: the first part is the investigation about consumer's personal information; the second part investigates the influence that the relevant factors engage in consumers' decision making. The scale separates the questions into 5 major categories:marketing and reputation, cost, performance, offline support and others.

The questionnaire is distributed and collected from March 25 to June 1, 2015. 539 questionnaires were collected in total.

The questionnaire needs to do a reliability test to suggest whether the collected data is amenable and reliable. Reliability represents the consistency and stability of a scale. In social science area, researchers use Cronbach's Alpha most often as the standard of a scale's reliability. Higher the value of Cronbach's Alpha means higher reliability of the scale and less error of the measurement. Under normal circumstances, the Cronbach's Alpha of a scale which is greater or equal than 0.6 means that the data is reliable. When the Cronbach's Alpha is greater than 0.8, it indicates that the reliability of the scale is ideal. By using thePASW Statistics18.0, figure 1 shows the reliability of the second part of the questionnaire. The testing result indicates that the Cronbach's Alpha of all 21 questions in the second part is 0.835 . It means that the collected data is consistent and stable that has high reliability, satisfying the need of researchers' general requirement.

Table 1: Reliability Statistics

\begin{tabular}{|c|c|}
\hline Cronbach's Alpha & Index \\
\hline .835 & 21 \\
\hline
\end{tabular}

\section{Analysis of Consumers' Behavior}

\subsection{The influential factors on purchasing new energy vehicles}

The questionnaire lists 20 potential factors that require informants rank the level of importance respectively. The collected data shows that security is the most important factor to consumers with the highest score 4.75. After-sale service and supporting facility are also the main concerns to consumers when they make decision on purchasing new energy vehicles. Maintenance cost, comfortability, consumers word-of-mouth and usage cost have remarkable impact on consumers' decision making as well. Fashion and fancy, recommendation from family, friends or colleges and advertisement are the least factors that affect the purchasing of new energy vehicles.

The bivariate analysis is an effective method to test the relevance between two factors. For there are 20 potential factors that may influence consumers decision making on purchasing new energy vehicles, using bivariate analysis aims to study whether the personal information has impact on those potential factors, therefore the following suggestions on improving the development of new energy vehicles industry can be more specific.

According to the calculated result from PASW Statistics18.0, each item in the personal information has relevance with the potential factors more or less. Compared with women, it is significant that men tend to care more about recommendation and word-of-mouth. And they also concern more about the performance of security and power of the new energy vehicles. The usage cost and maintenance cost are important factors when they make a decision.

People in different age have different thoughts on purchasing new energy vehicles. It is noticeable that older people are highly influenced by advertisement and recommendation. And the convenience of lotting number is the issue they concern when they purchasing a new energy vehicle.

It is remarkable that people with higher level of education focus more about the environmental issue about the new energy vehicles. When making a decision, they show more concerns on usage cost and maintenance cost.

People with higher disposable income tend to be affected by advertisement and recommendation which is the same as older people. 
The collected data indicates that when and whether to purchase a new energy vehicle, the purchasing subsidy and comfortability are individuals' thoughts that do not have a remarkable relevance with the personal background.

\subsection{The proportion of the influential factors on purchasing new energy vehicles}

In reality, the influential factor on whether to purchase a new energy vehicle is not a single one. Therefore, it is sensible to use multivariable linear regression model to integrate the multiple factors, weighting the proportion and have an overall consideration.

By using PASW Statistics18.0, the definition of each potential factor and the calculated formula of proportion are as table 2 and equation 1 :

Table 2: Value Assignment

\begin{tabular}{|c|c|}
\hline $\mathrm{x}_{1}=$ advertisement & $\begin{array}{c}\mathrm{x}_{11}=\begin{array}{c}\text { maintenance } \\
\text { cost }\end{array} \\
\end{array}$ \\
\hline $\begin{array}{c}\mathrm{x}_{2}=\text { environmental } \\
\text { pollution }\end{array}$ & $\mathrm{x}_{12}=$ decoration \\
\hline $\begin{array}{c}\mathrm{x}_{3}=\text { convenience of } \\
\text { lotting number }\end{array}$ & $\mathrm{x}_{13}=$ comfortability \\
\hline $\begin{array}{l}\mathrm{x}_{4}=\text { fashion and } \\
\text { fancy }\end{array}$ & $\mathrm{x}_{14}=$ security \\
\hline $\begin{array}{l}\mathrm{x}_{5}= \\
\quad \text { recommendatio } \\
\mathrm{n}\end{array}$ & $\mathrm{x}_{15}=$ power \\
\hline $\begin{array}{c}\mathrm{x}_{6}=\text { purchasing } \\
\text { subsidy }\end{array}$ & $\begin{array}{c}\mathrm{x}_{16}=\begin{array}{c}\text { after-sale } \\
\text { service }\end{array} \\
\end{array}$ \\
\hline $\mathrm{x}_{7}=$ usage cost & $\mathrm{x}_{17}=$ gender \\
\hline $\mathrm{x}_{8}=$ word-of-mouth & $\mathrm{x}_{18}=$ age \\
\hline $\mathrm{X}_{9}=$ sales price & $\mathrm{x}_{19}=$ education \\
\hline $\begin{array}{c}\mathrm{x}_{10}=\text { supporting } \\
\text { facility }\end{array}$ & $\begin{array}{c}\mathrm{x}_{20}=\begin{array}{c}\text { disposable } \\
\text { income }\end{array} \\
\end{array}$ \\
\hline \multicolumn{2}{|c|}{$\begin{aligned} \mathrm{y}= & -0.735 \mathrm{x}_{1}+3.407 \mathrm{x}_{2}+0.202 \mathrm{x}_{3} \\
& +0.817 \mathrm{x}_{4}+0.209 \mathrm{x}_{5}+0.109 \mathrm{x}_{6} \\
& +0.445 \mathrm{x}_{7}-0.564 \mathrm{x}_{8}-1.896 \mathrm{x}_{9} \\
& +1.046 \mathrm{x}_{10}-1.434 \mathrm{x}_{11}+0.509 \mathrm{x}_{12} \\
& -0.275 \mathrm{x}_{13}+0.122 \mathrm{x}_{14}+0.793 \mathrm{x}_{15} \\
& +0.387 \mathrm{x}_{16}+1.856 \mathrm{x}_{17}+0.716 \mathrm{x}_{18} \\
& +0.766 \mathrm{x}_{19}-1.110 \mathrm{x}_{20}\end{aligned}$} \\
\hline
\end{tabular}

\section{CONCLUSIONS}

\subsection{Discussion}

Within all the 20 potential influential factors, most people tend to purchase a new energy vehicle in that it relieves the environmental pollution. It shows that with the development of society, the awareness of protecting the surrounding environment has risen up. But still, people with low level of education are lack of the awareness compared with people who get high level of education. Gender also contributes a certain part to decision making. Men and women have different concerns on purchasing new energy vehicles. From the analysis, it can be seen that men study new energy vehicles from the outside, the public, which means that if there are more provided information, it may increase the chance for men to purchase a new energy vehicle. The relevant support, performance of security and after-sales service directly influence consumers' decision which indicates that consumers purchase a new energy vehicle not for curiousness, but for practical use. They expect new energy vehicle as a useful substitute of walking which can not only help with the environment, but also be efficiently and effectively used.

\subsection{Suggestion of new energy vehicles development in Chinese market}

The actions on developing new energy vehicles in developed countries are available. Through the investigation, the conclusion represents the current influential factors that affect consumers' decision making on purchasing new energy vehicles. Taking all the current information into consideration, the strategy can be divided into three sectors: technology, management and marketing.

It is government's responsibility to invest more funds into researching the core technology of the new energy vehicles. Though the Chinese government has already spent vast money into the new energy vehicles program, in order to have a breakthrough on the bottleneck, the research still needs abundant government support, sending more intelligent scientists and putting more funds.

In terms of the management mode, the scale of production should be enlarged and the operating cost should be decreased. Though China must innovate its own suited way on studying new energy vehicles, it is sensible to mimic developed countries' management mode as a reference. Only proposing several demonstration promote pilot cities is not enough, the Chinese government should enact more relevant beneficial policies to encourage the enterprises enlarging the scale of production and reduce the operating cost which can let new energy vehicles more easily to enter the consumer market.

The Chinese governmentshould promote the awareness and spread more updated information to the public, and enlarge the offline support at the same time. More education can improve public awareness of theenvironment protection, so do thepropaganda. More public advertisement can enhance the sense of identity around the whole society, which can work by giving more information about the performance and maintenance of the new energy vehicles. Furthermore, building more offline supports such as charging pile is highly useful to enlarge the new energy vehicle industry for consumers regard this issue as one of the most important factors when they make decision.

The popularization of the new energy vehicles will not as quick as being expected. Without any exaggeration, it should be acknowledged as a long-term challenge. Enacting 
the policies and waiting the reaction of market all need time to adapt. But what is certain is that in the future, the market will be more elaborated into specific parts to provide multiple targeted services.

\section{References}

[1] http://d.wanfangdata.com.cn/Thesis_D211386.aspx

[2] Z. Zhang and F. Zhao, "The Study of The Different Development Strategy of New Energy Vehicles Between China and America," Studies in Science of Science, Vol.32, No.4, 2014.
[3] Y. Chen and X.F. Wang, "The Analysis of Development Strategy and Bottleneck on Chinese New Energy Vehicles under the Industrial Chain Perspective," Lanzhou Academic Journal, 2014(8).

[4] M.G. Ouyang, "The Development Strategy of Chinese New Energy Vehicles," Automotive Engineerig, Vol.28, No.4, 2006.

[5] D.Y. Qian, "The Study of Strategy on Chinese New Energy Vehicles Industry under the LC Background," Economic Review, 2011(2).

[6] C.M. Ma, "The Study of Chinese New Energy Vehicles Industry Development Based on Foreign Experience," Academic Exchange, Serial No.213, No.12, 2011. 